\title{
EDITORIAL DE NIHILO NIHILUM
}

Agradezco a la actual Dirección de la Facultad de Derecho de la Pontificia Universidad Católica de Chile, compuesta por los profesores, don Roberto Guerrero, don Carlos Frontaura y don Gabriel Bocksang, el altísimo honor de haberme nombrado Director de esta prestigiosa colección periódica.

Como se sabe, nuestra Facultad, con cerca de 125 años de existencia, tuvo otras experiencias editoriales anteriores de gran importancia: los Anales Jurídico-Sociales (1936-1962) y los Estudios Jurídicos (1972-1973). La Revista Chilena de Derecho, en tanto, nació en 1974, bajo la Dirección del Prof. don Jaime Navarrete Barrueto. De modo que sus 38 años de ininterrumpida emisión la transforman en la revista jurídica-universitaria vigente más longeva de nuestro país.

Cuando nuestra Revista cumplió 25 años, el discurso académico principal de la celebración estuvo a cargo del notable colega, Prof. don Alejandro Guzmán Brito. En la ocasión, puso de relieve la continuidad de nuestra publicación y la estabilidad de sus contenidos; tal como se había propuesto en su lanzamiento, en el mencionado año 1974, por el Decano, Prof. don Sergio Gaete. Pero, en honor a la verdad, el Decano Gaete había formulado otro objetivo adicional, que hacia 1999 se había cumplido solo parcialmente: transformar la revista en "un vehículo de comunicación de la actividad jurídica chilena con la extranjera". Este deseo institucional no había quedado, sin embargo, en el olvido ni para el Decano de la época de la celebración de los 25 años, Prof. don Raúl Lecaros, ni para su Director, Prof. don Alejandro Vergara (1997-2007).

Precisamente, gracias a la perseverancia, dedicación y experiencia como investigador de este último, se produjo un avance de grandes consecuencias en este sentido: la incorporación de la Revista, a partir del año 2006, en la Scientific Electronic Library Online (SciELO).

Más tarde, en el año 2009, le correspondió organizar la celebración de los 35 años de la Revista a su sucesora en esta Dirección, Profa. doña Ángela Vivanco (2007-2012), bajo el auspicio del Decano, Prof. don Arturo Yrarrázaval. En dicha oportunidad, ella me honró ofreciéndome la conferencia principal del acto $-y$, a decir verdad, en aquella época yo no podía ni imaginar que algún día esta publicación, tan querida para mí, llegaría a quedar bajo mi cuidado-. Las cosas habían mejorado muchísimo en los diez años transcurridos, gracias al buen hacer de ambos Directores. Esto se observaba desde varios ángulos: la internacionalización de los autores; la diversificación de sus temáticas; y, la ostensible mejoría general de las producciones de los juristas nacionales, impulsada especialmente por el apoyo de FONDECYT. Además de la ya referida incorporación de la Revista al consorcio SciELO, se debía tener en cuenta su inclusión en otros índices internacionales de gran relevancia, como Scopus, y su publicación íntegra y a texto completo en el portal Dialnet, en España.

El brillante, fino y ordenado trabajo de la Profa. Vivanco, por cierto, ha permitido que esta Revista sea, hoy, la más "descargada" en el sitio web de SciELO y en el de Dialnet. 
La coronación de su trabajo cristalizó este mismo año, hacia el final de su período como Directora, con el hito más significativo en toda la historia de esta Revista: la aceptación retroactiva, desde 2010, en la Web of Science ("ISI”); esto es, en los siguientes índices de Thomson-Reuters: Social Sciences Citation Index®; Journal Citation Reports/Social Sciences Edition; Current Contents®/Social and Behavioral Sciences.

Gracias a este reconocimiento, nuestra Revista pasó a ser la primera de carácter general, en lengua castellana, en ser incorporada a un universo de solo 143 revistas de derecho en todo el mundo. En lo que se refiere a las revistas de habla hispana, accedió asimismo al selecto grupo universitario conformado tan solo por la publicación chilena "Estudios Constitucionales" y por las españolas "Revista de Derecho Comunitario Europeo" y "Revista Española de Derecho Constitucional".

Las tareas para el futuro son tan gravosas como ambiciosas. Tal como nuestra Facultad está alcanzando internacionalmente el reconocimiento de Facultad Global que se ha propuesto, la revista también debe seguir la misma senda. Es necesario incorporarla en más índices, cadenas de distribución y plataformas que aumenten su "visibilidad" en el mundo; al mismo tiempo, debe seguir constituyendo el principal medio de comunicación para los mejores juristas nacionales; y, también, debe consolidarse como una herramienta de primera calidad, tanto para la formación de los alumnos de derecho como de todos aquellos que deseen profundizar sus conocimientos jurídicos.

La Revista Chilena de Derecho, de la Facultad de Derecho de la Pontificia Universidad Católica de Chile, está abierta a todos los mejores juristas del país y del mundo. Desde esta tribuna invito a todos a participar en ella, con la convicción -siempre presente en mi quehacer-, de que la seriedad en el trabajo, la imaginación, la capacidad creativa y la colaboración, son las claves fundamentales en toda empresa verdaderamente universitaria.

Prof. Dr. Patricio-Ignacio Carvajal 